\title{
ASPECTOS DA SOCIETAS ROMANA
}

\author{
ASPECTS OF THE ROMAN SOCIETAS
}

Renato Ventura Ribeiro

\begin{abstract}
Resumo:
$\mathrm{O}$ artigo apresenta alguns aspectos da societas romana, analisados não-só com base nas tradicionais fontes romanas. como também à luz das novas descobertas e da moderna doutrina romanística, para revisão de conceitos anteriores e estudos de Direito Comparado. Relata a origem e evolução mais provável do contrato de sociedade no Direito Romano e suas principais características. A partir disto, são analisadas as principais regras relativas à gestão social e responsabilidade dos sócios gestores. Em particular são examinados os argumentos das diversas correntes de pensamento sobre os critérios de responsabilidade no periodo clássico e as regras no Direito justinianeu. Por fim, o Autor discorre sobre a influência do caráter intuitus personae da societas nas relações sociais.
\end{abstract}

Palavras-chave: Direito Romano. Contrato de sociedade. Contrato de sociedade no Direito Romano. Socielas. Consortium ercto non cito. Responsabilidade dos sócios.

\begin{abstract}
:
The article details some aspects of the Roman societas, which are analyzed not only based on the traditional Roman sources, but also according to the new breakthroughs and the modern Roman doctrine, aiming at the revision of previous concepts and studies of comparative law. It describes the origin and the most likely evolution of the partnership agreement in the Roman Law and its main characteristics. In the light of this, the article analyzes the main rules that govern the term of administration and the responsibilities of the managing partners. In particular, it examines the arguments presented by the diverse lines of thought concerning the criteria of responsibility in the classical period and the rules in the Justinian Code. Finally, the author discourses on the influence of the societas intuitus personae nature in the social relations.
\end{abstract}

Keywords: The partnership agreement in the Roman Law. Partners Responsibility.

1. Introdução

O propósito do presente artigo é apresentar alguns aspectos da societas romana, analisados não só com base nas tradicionais fontes romanas, como também à luz das novas descobertas e da moderna doutrina romanística.

Mestre, Doutor e ex-Professor Assistente Temporário do Departamento de Direito Comercial da Faculdade de Direito da USP. 
O exame atualizado do contrato de sociedade no Direito Romano permite eventual revisão de conceitos anteriores e auxilia os pesquisadores, em especial os não romanistas nas menções à societas romana em estudos de Direito Comparado.

Foram escolhidos apenas alguns temas, em razão da limitação do espaço e da necessidade de seu maior aprofundamento, para que o presente estudo pudesse ter valia aos fins almejados.

2. Origem e evolução da societas romana

2.1. Do consortium ercto non cito à societas: opinião majoritária

Em Roma, durante o periodo de economia agrária dos primitivos tempos, havia o regime da propriedade coletiva. ' Os filhos, após a morte do paterfamilias, preservam em comum todo o patrimônio herdado e passam a explorá-lo em conjunto, formando o consórcio familiar (consortium ercto non cito $^{2}$ ). Isto, não só por solidariedade material e moral, como também por proteção, em razão das guerras frequentes, ${ }^{3}$ sendo a manutenção da unidade fundiária um fator da expansão romana. ${ }^{4}$ Com base em textos que fazem referência ao consórcio, ${ }^{5}$ acredita-se que a societas romana tem por origem a comunhão hereditária.

A descoberta, em 1933, do fragmento gaiano de Antinoe que completou o palimpsesto de Verona, ${ }^{6}$ revela que Gaio, analisando o antigo consórcio, diz que o chamado consortium ercto non cito é uma sociedade legítima e natural (legitima simul et naturalis societas - $G$. 3, 154a), que não necessita de um ato constitutivo. ${ }^{7}$ Além desta

Por todos, cf. SZLECHTER, Le contral de socièté en Babylonie, en Grêce el à Romc. Paris, 1947. p. 170.

2 Sobre o significado da expressão erclo non cilo, ARANGIO-RUIZ, La societa in Diritto Romano. Napoli, Jovene, 1950, p. 3, nota 1, com rifferências bibliográficas. O entendimento predominante é que ercto vem de ercisco (dividir) e cito provém de cieo (provocar), dando a idéia de que o consórcio é um conjunto de bens indivisiveis. Subre o instituto, entre outros, vide ARANGIO-RUIZ, La societá.., cit., p. 3 e ss.; MARKY. Sociedade "ercto non cito", in Romanilas: Revista de cultura romana, I (1958), p. 40-60; GUTIÉRREZ-MASSON, Del "consortium " a la "societas" I: "Consortium ercto non cito", reimp. da I" Ed. Madrid, Universidad Complutense - Facultad de Derecho, Scccion de Publicaciones, 1994, p. 65-150.

3 Cf. DEL CHIARO, Le contrat de société en droit privé romain sous la République et au temps des jurisconsultes classiques. Paris, Sirey, 1928, à p. 20.

Cf. ARANGIO-RUIZ, La socieiá..., cit., p. 7, nota I

Vide, por excmplo, D. 17, 2, 3; D. 17, 2, 52, 6 e 8 .

Cf. G. 3, 154a - 154b. ARANGIO-RUIZ, La socielá..., cit., p. 3, nota 4 e ALBERTARIO, Studi di Diritlo Romano V: Storia. Metodologia. Esegesi. Milano, Giuffrè, 1937, p. 463, trazem uma relação bibliográfica dos diversos estudos apresentados sobre o fragmento. Apesar das tentativas para demonstrar glosas no manuscrito de Verona. tudo indica que não é alterado. já que há somente uma omissão em relação ao texto de Gain (cf. PUGLIESE, Istituzioni di Dirillo Romano. 2ª ed. Torino. Giappichelli, 1990, à p. 184).

Cf. D. $28,2,11$ 
sociedade dita natural, afirma existir outra, artificial, que pode ser constituída dirigindose ao pretor por meio de uma legis actio especial $(G .3,154 \mathrm{~b})$.

Tal passo permite um delineamento do que teria sido a evolução da societas romana. A partir do consórcio hereditário surge o consortium voluntarium, regulado pelo ius gentium, talvez para permitir que os herdeiros de um falecido sem filho pudessem se unir para explorar um bem, ${ }^{8}$ eis que, com o advento da Lei das XII Tábuas, a herança é passivel de divisão, ${ }^{9}$ por meio da actio familiae erciscundae. Como a continuidade da comunhão dos bens depende dos herdeiros, tem-se o consortium voluntarium, com os elementos próprios (consensum, res e ius fraternitatis).

A societas omnium bonorum é um contrato constituído pelo consenso. independente das relações familiares, mas mantendo a característica de comunhão universal dos bens $(G .3,154)$. Num outro momento, há a possibilidade de participação de terceiros, criando artificialmente uma comunidade deste tipo entre outras pessoas, por meio de uma forma especial voluntária (certa legis actio) perante o pretor, talvez uma in iure cessio transformada. ${ }^{10}$ Tem-se, então, o germe do contrato de sociedade, tal como concebemos hodiernamente.

A evolução do consórcio familiar para o contrato de sociedade, portanto, passa por duas etapas." Inicialmente, há a introdução do elemento vontade, com a existência de uma sociedade consensual, regulada pelo ius gentium. ${ }^{12}$ Após, admite-se a participação de terceiros. não familiares. numa segunda forma de sociedade que podia ser criada pelo mero consentimento das partes. ${ }^{13}$

\footnotetext{
Cf. ARANGIO-RUIZ. La società.... cit.. p. 14.

Cf. G. 4. 17a.

Cf., por todos, ARANGIO-RUIZ, La socierà..., cit., p. 9-10.

Cf. ARANGIO-RUIZ, La sociela..., cit., p. 3-20, em especial à p. 20.
}

12 A societas omnium bonorum era submetida às normas do ius gentium e não do ius civilc porque as normas do último, que regulavam o consortium ercto non cito, cram próprias adequadas somente para disciplinar a sociedade agricola e não outras atividades, e com a expansão das fronteiras romanas e novos habitantes estrangeiros, torna-se necessária a existência de um modelo de sociedade que pudesse ser utilizado por toda a populaçăo. A respeito. cf. AZEVEDO, Dissociação da sociedade mercantil. São Paulo, Resenha Universitária, 1975, à p. 6.

3 Sobre sociedade como um contrato consensual, vide DAUBE. Societas as consensual contract, in The Cambridge L.mv Journal. 1938. p. 381-403. 
2.2. Opiniões diversas

Outras teses tentam explicar a origem e evolução do contrato de sociedade. Karlowa ${ }^{14}$ sustenta que, no início, tem-se apenas a propriedade de uma coisa comum. Com o desenvolvimento da atividade econômica, gera-se a relação jurídica e é reconhecido o acordo, tendo ou não havido a cooperação dos sócios com bens materiais. Sociedade é um contrato, enquanto consórcio é situação puramente sucessorial. É apoiado por Szlechter ${ }^{15}$ que, todavia, acredita que é requisito essencial para a formação do contrato de sociedade a conferência material de bens.

Já para $\mathrm{Cuq}^{16}$ a mais antiga forma de sociedade é a societas quaestus. Trata-se de uma sociedade financeira, constituída por publicanos para fornecer armamentos ao exército e prestar serviços públicos, muito comum no período das guerras púnicas. No tempo de Catão, o Antigo, há referências às sociedades de trabalhadores agrícolas que alugam seus serviços por ocasião das colheitas.

Contrapondo-se à idéia de que a societas tem uma origem única, alguns autores defendem a idéia de que os diversos tipos de societas têm origens distintas.

Dentre estes, a teoria mais aceita é a de Pernice. ${ }^{17}$ Para o jurista, a societas omnium bonorum é derivada do consortium; a societas universorum quae ex quaestu veniunt, a societas alicuius negotiationis e a societas vectigalium provêm de associações mercantis e a societas unius rei tem origem na politio. Isto porque a fórmula primitiva da actio pro socio do Edito do Pretor é relativa somente à societas omnium bonorum ${ }^{18}$ e o beneficium competentiae só deve ser aplicado aos associados de todos os bens. ${ }^{19} \mathrm{~A}$ ação de sócio acarreta a pena de infâmia, diferentemente da actio familiae erciscundae. Além disto, a sociedade extingue-se com a morte de um dos sócios (D. 17, 2, 59 pr.; D. 17. 2, $65,9 ; G .3,152)$, ao contrário de consórcio. Já a idéia de lucro e negociações, presente em $D .17,2,7$ a 9 , indica a origem das sociedades nas corporações comerciais.

Os críticos de Pernice explicam que a aplicação da fórmula primitiva da actio pro socio e do beneficium competentiae somente no âmbito da socictas omnium

14 Cf. Römische Rechtsgeschichte, II. Leipzig, Von Veit, 1901, p. 652-3.

is Cf. Le contrat de société..., cit., p. 215 e 245 e ss.

16 Cf. Manuel des institutions juridiques des romains, $1^{2}$ ed., Paris, Plon, 1917, p. 493.

17 Cf., por todos, Parerga I: Zum römischen Gesellschafisvertrage, in ZSS 3 (1882), p. 48-103. às p. 48-9. Apóiam esta tese FERRINI, Le origini del contralto di societa in Roma, in Opere di Contardo Ferrini III: Studi vari di diritto romano e moderno sulle obbligazioni, sul negozio giuridico, sulle presunzioni. Milano, Hoepli. 1929, p. 17-48 (=AG 38 (1887), p. 3-32), p. 15; GIRARD, Manuel élémentaire de droit romain, 4" ed., Paris, Arthur Rousseau, 1906, p. 574: PACCHIONI, Corso di diritlo romano III. Torino, UTET, 1922, p. 251-2: BONFANTE, Istituzioni di diritto romano, 10ª ed., Torino. Giappıchelli, 1946, p. 494.

18 Cf. Edictum Perpetumm, $\$ 109$.

19 Embora depois o beneficium competentiae passa a ser aplicado a todos os tipos de sociedades, como scrá visto no item 4 abaixo. 
bonorum pode indicar apenas que ela é uma primeira forma de sociedade. Até porque, mais tarde, o beneficium competentiae é estendido às demais sociedades. ${ }^{20} \mathrm{O}$ caráter infamante da actio pro socio apenas reforça o caráter intuitu personae da sociedade. mostrando uma relação mais íntima e uma maior presença da fides entre os contratantes, o que acaba até por aproximar a societas do consórcio. A extinção da sociedade pela morte de um dos sócios pode ser resultante do acordo de vontades. ${ }^{21} \mathrm{E}$ a idéia de lucro é resultante do desenvolvimento comercial posterior.

Para Del Chiaro ${ }^{22}$ e Poggi $^{23}$ o consortium ercto non cito é instituição própria do ius civile e, portanto, utilizada somente pelos romanos, enquanto a societas omnium bonorum é instituto do ius gentium, utilizada também por estrangeiros. No entanto, como o ius gentium traz um complemento ao ius civile, reforça-se a idéia de que a societas omnium bonorum deriva do consortium ercto non cito, não sendo um instituto distinto. $^{24}$

Outros autores, como Giffard, ${ }^{25} \mathrm{Kaser}^{26}$ e Burdese, ${ }^{27}$ vislumbram uma dupla origem da societas: a societas omnium bonorum seria derivada do consórcio e a societas alicuius negotiationis das associações comerciais, que atuam no comércio internacional. Já Arangio-Ruiz ${ }^{28}$ acredita que a societas omnium bonorum provém da societas alicuius negotiationis e da societas publicanorum.

Não-obstante as teses acima mencionadas, prevalece a teoria monista da origem da societas, em razão dos textos de Gaio ( $G$. 3, 154a e b), do conceito unitário do instituto e uniformidade de regras existentes no Direito clássico, como a fórmula da actio pro socio prevista no Edito do Pretor, o caráter fraternal e não especulativo da societas omnium bonorum. ${ }^{29}$

20 Cr. D. 17, 2, 63 pr. e item 4 infra.

21 Vide COSTA, Storia del Diritto Romano dal origini alle compilazioni giustinianee. Torino, Fratelli Bocca, 1911 , p. 377, nota n. 1.

22 Cf. DEL CHIARO, Le contrat de société..., cit., p. 52, nota 3.

23 Cf. Il contratto di societá in diritlo romano classico. Roma, "L'Erma" di Bretschneider, 1972, p. 62.

${ }_{24}$ Cf. GUTIÉRREZ-MASSON, Del "consorrium" a la "societas"... cit., p. 35-38, em especial p. 38.

25 Cf. Précis de Droit Romain II: Obligations, $2^{\lrcorner}$ed., Paris, Dalloz, 1934, p. 74-75.

26 Cf. Das Römische Privarrecht I: das altrömische, das vorklassische und klassische recht. München, Beck, 1955 (tradução espanhola da $5^{\text {a }}$ ed. alemã por José Santa Cruz Teijeiro, Derecho romano privado. $2^{2}$ ed., Madrid, Reus, 1982), p. 202.

27 Cf. Manuale di Dirillo Privato Romano. Torino, UTET, 1964, p. 546.

28 Cf. La società..., cit.. p. 20 e seguintes, em especial p. 28.

29 Por todos, vide COSTA, Sıoria del diritlo romano.... cit.. p. 376 e GLTIÉRREZ-MASSON. Del "consortium" a la "socuetas"..., cit., p. 49-79. 
3. Natureza jurídica: societas como contrato consensual

A societas romana tem por forma de constituição a consensualidade ${ }^{30}$ que decorre da sponsio ou da stipulatio, ${ }^{31}$ com os contratantes obrigando-se reciprocamente a um oportere ex fide bona ${ }^{32}$ Não pressupõe necessariamente o lucro nem uma atividade econômica, podendo ser um conjunto de bens. ${ }^{33}$

O consentimento dos sócios pode manifestar-se de qualquer forma ${ }^{34}$ mas deve ser permanente ${ }^{35}$ e não se presume, ${ }^{36}$ sendo expresso com o animus contrahendae societatis ou affectio societatis, ${ }^{37}$ No entanto, em razão da suspeita de alterações nos textos relativos à affectio societatis, ${ }^{38}$ discute-se a sua necessidade na constituição da sociedade no período clássico. A questão é bastante controvertida. Importa saber se a ausência de affectio societatis implica na inexistência da sociedade, configurando situação de indivisão. ${ }^{39}$ Schulz ${ }^{40}$ defende a interpolação dos textos que mencionam a affectio societatis, porém afirma ser a mesma desnecessária à constituição da sociedade, uma vez que a única exigência para tanto deve ser, no seu entender, a cooperação para consecução de um fim comum. Assim, mesmo não sendo clássica a affectio societatis, permanece a sociedade como um contrato consensual, ao requerer apenas o consentimento inicial das partes.

É dificil precisar o exato momento da concepção da sociedade como um contrato consensual. Alguns autores, ${ }^{41}$ com base em D. 17. 2, 52, 8, afirmam ser o consórcio voluntário uma forma de sociedade. Segundo Costa, ${ }^{42}$ antes de Cícero não há documentos que assegurem a existência da societas na acepção técnica e jurídica do termo. E, consoante o texto gaiano, o consórcio familiar não mais existe na época clássica, ${ }^{43}$ embora influencie a sociedade universal do direito clássico. ${ }^{44}$

3n A respeito da sociedade como um contrato consensual, vide em especial as obras de (iUARINO, Societas consensu contracta. Napoli, Scientifica, 1972, e BONA, Studi sulla società consensuale in Diritfo Romano. Milano, Giuffrè, 1973, p. 7-79.

Cf., por todos, GIFFARD, Précis..., cit., p. 89, n. 2.

Cf. $G .3,135$.

Cf. D. 17, 2, 5: D. 17.2. 7-13 e D. 17,2, 52, 13.

Cf. D. $17,2,4$ pr. \& $G .3,154$.

Cf. $G .3,151 ; 1.3,25,4$ e C. $4,37,5$.

D. $17,2,52,6$.

CF. D. 17, 2. 31 e $32 ;$ D. 17, 2, 37; D. 17, 2, 44: G. 3, 151; C. 4, 37, 2.

38 Pela a aplicação clássica da affectio societatis, vide, entre outros, ARANGIO-RUIZ, La societá..., cit., p. 67 et seq.

39 Cf. GIRARD, Manuel..., cit., p. 575, nota n. 3.

so Cf. Classical Roman Law. Oxford, Clarendon Press, 1951 (trad. espanhola de José Santa Cruz Teigeiro, Derecho Romano Classico, Barcelona, Bosch, 1960), p. 525.

$₫$ Cf, por todos. DEL CHIARO. Le contrar de sociéré..., cit., p. 110.

$\$ 2$ Cf. Storia del Dirillo Romano..., cit.. p. 379, nota n. 2. 
Uma característica dos períodos pré-clássico e clássico é a satisfação das novas exigências e reconhecimento dos valores sociais derivados do desenvolvimento comercial marítimo e terrestre e das recentes ou mais intensas atividades produtivas não agrícolas, como minerais, artesanais, industriais e financeiras..$^{45}$ Neste contexto, para atender as necessidades das novas relações econômicas, são criados os contratos consensuais, cuja praticidade favorece a instrumentalização das relações comerciais. ${ }^{46}$

Assim, entende a doutrina predominante ${ }^{47}$ que o reconhecimento da sociedade como contrato consensual se deu já na época clássica nas transações entre romanos e estrangeiros, devido ao desenvolvimento econômico após as conquistas no Mediterrâneo e na fides, que é um elemento vinculante nas várias relações sócioeconômicas do comércio. ${ }^{48}$

\subsection{Outras posições}

Alguns textos ${ }^{49}$ falam em sociedade voluntária, indicando a existência de uma sociedade não consensual. Nas fontes, o consórcio familiar é chamado de sociedade não consensual ${ }^{50}$ e socius aparece como sinônimo de co-proprietário. ${ }^{51}$ Isto indica que os romanos entendem por sociedade a co-propriedade ou o condomínio, formados sem a necessidade de um ato constitutivo, e por sociedade voluntária o contrato de sociedade celebrado mediante uma formalidade especial, como demonstra $G .3,154$ e 154 b.

43 Embora haja quem, com base em $D .44,7,57$. acredite que a expressão aliud gemus se rufere ao consórcio. Uma critica a tal posição é apresentada por ARANGIO-RUIZ, La società..., cit., p. 57.

44 Cf., por todos, GARRIDO, Derecho privado romano: acciones, casos, instituciones, $4^{\mathrm{a}} \mathrm{cd}$. (reimpressão). Madrid, Dykinson, 1989, p. 615.

45 Cf. PUGLIESE, Istituzioni..., cit., p. 185.

46 A propósito, o relato de ARANGIO-RUIZ, La società..., cit.. p. 27-28: "... Come tutti sanno, via via che la potenza romana, superati i confini dell'Italia, si è trovata in rapporto con gli altri paesi del bacino del Mediterraneo, e soprattutto con le città della costa e dell'arcipelago greco, un numcro sempre maggiore di cittadini si è dedicato al commercio. Roma diveniva enormemente ricca. c i prodotti di lusso, a cominciarc dagli schiavi specializzati vi erano molto richiesti, il che offriva alla privata iniziativa un campo sterminato: mentre in tutti i centri commerciali molti cives Romuni s'installavano a scopo di traffico, altri si faccvano armatori e capitani di navi. E certo le operazioni commerciali esigevano relazioni continuc coi mercanti di ogni altro paese. É cosi che sono nati i quattro contratti del ius gentitum: compravendita, locazione conduzione, mandato, società; non del tutto nuovi nel loro contenuto economico, che anzi già fra romani era il più delle volte già realizzabile per altra via - specialmente. come or ora si è detto, attraverso la forma della stipulazione -, ma resi più agili e più accetti ad uomini di diversa provenienza da ció che l'accordo delle volonta bastava ormai da solo a porre in essere le reciproche obblıgazioni."

\$7 Por todos, vide GUARINO, Societas.... cit., p. 112 , nota n. 6.

s8 Cf. Cícero, pro Roscio Amer. 40, 116: in Verrem. 2. 3. 58. 134. Sobre a importância da fides nu tráfego internacional da época. vide nota n. 46 supra.

is Cr. D. $17,2,63,8 ; D .10,2,25,16 ;$ D. $44,7,57$.

so ARANGIO-RUIZ, La societá... cit.. p. 5-18, observa que, apesar das diversas teses sobre o primitivo consórció. é certo que o instituto. por ser arcaico, não se submete a uma rigorosa classificaçâo.

si Cf. $G, 4,42$. 
Por isto, parte da doutrina ${ }^{52}$ acredita que a sociedade é uma continuidade do consortium, negando que na época clássica é constituida por um contrato consensual. Fundamenta sua argumentação na existência do consortium voluntarium na época clássica (hoje conhecido por societas omnium bonorum), no ius quodammodo fraternitatis, na estrutura da actio pro socio e na pena de infâmia. Não-obstante a imprecisão terminológica dos romanos, consórcio e sociedade são institutos bastante distintos. Ao contrário da sociedade, o consórcio não necessita de ato constitutivo, independe de consenso, é formado somente por herdeiros, não se dissolve com a morte dos sócios, não permite renúncia, não é afetado pela capitis deminutio de seus membros e está sujeito à aplicação da actio familiae erciscundae, que não é infamante. ${ }^{53}$

Com base nas idéias de Bonfante, ${ }^{54}$ seus discípulos ${ }^{55}$ acreditam que 0 consórcio ercto non cito é um condomínio. Justificam a teoria com base na copropriedade em partes iguais, na indisponibilidade do patrimônio por ato de um condômino, no uso do termo socius como sinônimo de co-proprietário e condômino, na larga abrangência do conceito de contractus, na menção, em $G$. 3, 154 e 154b, de dois tipos de sociedade (uma consensual, outra identificada com o consórcio), no tratamento conjunto de sociedade e condomínio nas obras de Múcio Scevola e Massúrio Sabino e na possibilidade, em alguns casos, da utilização, indistintamente, da actio pro socio ou da actio communi dividundo.

Contudo, a grande maioria dos autores ${ }^{56}$ ensina que os institutos não podem ser confundidos. A igualdade de termos não indica, necessariamente, identidade entre os institutos $^{5 /}$ e pode ser fruto de interpolações. Por sua vez, em $D .10,2,25,16$,

\$2 Os autores apontam como a principal obra sobre o tema a de WIEACKER. Societas. Hausgemeinschaft und Erwerbsgesellschaft I. Weimar, Nachfolger, 1936. p. 153 e ss. Como criticas à tese de WIEACKER, vide as apresentadas por DAUBE, Societas..., cit., p. 384 e ss. ¿ARANGIO-RUIZ, La società..., cit., p. 62. ALBERTARIO, Studi di Diritto Romano III: Obbligazioni. Milano: Giuffrè, 1936. p. 106, nota n. 4; FREZZA, Actio communi dividundo. RISG, Nova Série, n. 7 p. 3-142, 1932; EIN, Le azioni tra condomini, BIDR 39 (1931), p. 73-294, às p. 76-138 e 292: BORETTINI, Societas ce communio in due recenti studi romanistici, RISG. Nova Série, 7 (1932), p. 458-475.

Sobre a diferença entre sociedade e comunhão, vide MOLITOR, Les obligations en droit romain 11. 12. ed. Paris: Auguste Durand. 1867. p. 1-5, que aponta como elementos distintivos a convenção, disposição legal e possibilidade de liberalidade de terceiros; DEL CHIARO, Le contrat de société..., cit., p. 14-15; ARNÓ, II contratto di società. Torino: Giappichelli, 1938. p. II5-120; ARANGIO-RUIZ, La socielá.., cit., p. 3250 e bibliografia citada por GUARINO. Diritto privato romano. 8. ed. Napoli: Jovene, 1988. p. 813, nota n. 88.11. No direito modemo, cf. ainda INNOCENTI, L'esclusione del socio. Padova: CEDAM, 1956. p. $12 \mathrm{c}$ notas 2 e 3 . Por fim, sobre as relações entre sociedade e comunhão, cf. AZEVEDO, Dissociação.... cit., p. 1-25.

57 Em razão da diversidade de significado dos termos socius e societas, alerta GUARINO, Diritto privato romano. cit., p. 813, nuta 88.1.: "Una ricostruzione della socielas consensuale romana non può essere, dunque, affidata troppo fiduciosamente alla terminologia. ma deve, piú di ogni altra ricostruzione, mirare 
afirma-se expressamente que a comunhão não é um contrato. Também não há. ao tempo de Gaio, dois tipos de sociedade, vez que o próprio jurista relata não mais existir o consórcio, sendo temerária a feitura de uma excursus neste sentido, com base no texto gaiano e no Edito do Pretor. O enfoque conjunto dos institutos pelos tratadistas da época pode tão somente demonstrar uma relação ou confusão entre os assuntos, mas não sua identidade. A actio pro socio, em face de seu caráter pessoal, é aplicada à sociedade, enquanto que na comunhão tem lugar a actio communi dividundo, de natureza mista. E o grande traço diferenciador dos institutos é a presença do consenso no contrato de sociedade, como amplamente exposto nas fontes. ${ }^{58}$

Já Bianchinis9 defende a existência, na época clássica, de dois tipos de sociedade universal: a societas totorum bonorum ou universarum fortunarum, de natureza contratual, regulada pelo ius gentium, e outra, própria do ius civile (societas omnium bonorum iuris civile), constituída através de uma forma de legis actio, nos moldes da societas ercto non cito. Esta última é a societas omnium bonorum, mencionada em $G .3,154 \mathrm{a}$. No entanto, como já visto, o consentimento presente na formação da societas omnium bonorum aponta para a existência de um vínculo contratual, havendo, portanto, uma só espécie de sociedade universal. ${ }^{60}$

\section{Características principais da societas}

A provável origem derivada do consortium ercto non cito explica a adoção de algumas regras singulares à societas, como o caráter intuitu personae e a aplicação do ius quodammodo fraternitatis.

O caráter intuitus personae da societas encontra explicação em sua origem. Provavelmente derivada do consórcio familiar (consortium ercto non cito), a societas é agrupamento de indivíduos e não de capitais, ${ }^{61}$ podendo ser apenas conjunto de bens, ${ }^{62}$ sem o propósito de lucro ou de exercício de atividade econômica. Baseia-se nas relações pessoais entre seus membros, com estreitos vínculos de recíproca confiança e a presença da fides ${ }^{63}$ o que explica algumas de suas regras, como a pena de infâmia, ${ }^{64}$ a

all'individuazione dei fatti caratterizzanti l'istituto dal punto di vista del diritto"

58 Cf., entre outros, D. 17, 2, 52, 8; D. 17, 2, 31-33; D. 17, 2, 4 pr.; D. 17, 2, 19; G. 3, 135-137 e 151 .

s9 Cf. Studi sulla societas. Milano: Giuffrè, 1967. primeira parte.

60 Contra a tese de BIANCHINI, vide especialmente BONA, Società universale e societa questuaria generale in diritto romano (a proposıto di M. Bianchini, Studi sulla "societas"). SDHI 33 (1967), p. 366389.

6! DEL CHIARO, Le contrat de société en droit privé romain sous la République et au temps des jurisconsultes classiques. Paris: Sirey, 1928. p. II.

62 Cf. nota n. 33 acima.

63 G. 3, 135 .

${ }^{64}$ D. $3,2,1 ; G .4,182$ e $1.4 .16,2$. 
relação fraternal (ius quodammodo fraternitatis), ${ }^{\text {os }}$ o beneficium competentiae e a extinção da sociedade pela morte ou capitis deminutio ${ }^{66}$ do sócio.

Em consequência do ius quodammodo fraternitatis aplica-se o beneficium competentiae $^{67}$ limitando a condenação do sócio ao que ele possa pagar (in id quod facere socius potest $)^{68}$ Há uma divergência entre os textos que tratam do beneficium competentiae na sociedade. Em $D .42,1,16$ a aplicação do instituto limita-se à societas omnium bonorum. Já em D. 17, 2, 63 pr., bastante suspeito de interpolação, o benefício estende-se à societas unius rei. Tenta-se explicar a dualidade pelo fato de ser utilizado inicialmente na societas omnium bonorum e mais tarde incidir nos demais tipos de sociedade. ${ }^{69}$ Isto porque, no direito clássico, o beneficium competentiae visa evitar a execução pessoal do devedor. em face da responsabilidade não apenas patrimonial, mas também pessoal pelo adimplemento das obrigações. Como privilégio pessoal, atinge apenas os membros da societas omnium bonorum, em razão da derivação da comunhão hereditária. Note-se que a benevolência é apenas patrimonial, pois, não-obstante a redução da dívida, permanece a pena de infâmia. No Direito justinianeu, a finalidade do instituto é evitar que o devedor seja privado dos meios indispensáveis à sua sobrevivência, motivo que abrange todas as sociedades. ${ }^{70}$ A mudança de finalidade do instituto é perfeitamente compreensível, em razão da evolução do pensamento jurídico romano com, por exemplo, o fim da execução pessoal do devedor e a introdução do pactum ut minus solvatur."

\section{D. $17,2,63 \mathrm{pr}$.}

Cf. D. $17,2,59$ pr.; D. $17,2,65,9 ; G .3,152-153$.

67 Referindo-se ao beneficium competentiae, as mais recentes obras são de GUARINO, La condanna nei limiti del possible. 2. ed. Napoli: Jovene, 1978; GILDEMESITER, Das beneficium comperentiae im klassischen römischen Rechr. Güttingen: Schwartz, 1986 c POVEDA VELASCO. Beneficium Competentiae, tese, São Paulo, FDUSP, 1996.

68 Cr. D. 17, 2,63 рr.: D. 42.1.16;I. 4, 16, 2 е I. 4, 6, 38.

69 POVEDA VELASCO, Beneficium competentiae, cit., p. 28-36, relata que são três as hipóteses para explicar a contradição entre as lontes: o remanejamento de $D .17,2,63$ pr., para incluir a aplicação do instituto no âmbito da societas unius rei; a alteração de $D .42,1,16$, limitando o privilégio ou então a restauração de ambos. partindo-se da premissa de que o beneficium competentiae não se aplica à sociedade. E, ao final do seu trabalho (idem, p. 125) acompanha a tendência majoritária da doutrina. entendendo pelo uso original do instituto no âmbito da societas ommium bonorum e sua extensão posterior às demais sociedades.

70 ALVES, José Carlos Moreira. Direito romuno, cit., p. 38 e ARANGIO-RUIZ, La societá..., cit., p. 183.

7 O pactum ut minus solvalur é um instituto que se assemelha à concordata moderna, permitindo aos herdeiros onerados com débitos a realização de um pacta com os credores que representam a maioria dos créditos para redução do débito. que vinculava todos os credores, ainda que não concordassem com os termos do acordo. Sobre a evolução da execução no Direito Romano e introdução do instituto, cf. MARCHI, Concurso de credores e pactum ut minus solvatur, Del Grifo, 1997, p. 41 e ss.. 
Como anota Schulz," as normas clássicas que regulam a sociedade trazem traços liberais e individualistas, mostrando também a aversão dos romanos a toda forma de societas. O contrato gera somente um mínimo de obrigações e as regras juridicas respeitam a liberdade individual, o que também prevalece no periodo pós-clássico.

As fontes de Direito Romano não trazem normas expressas a respeito da administração da sociedade, razão pela qual é provável que as normas relativas à gestão social sejam estabelecidas no contrato. ${ }^{73} \mathrm{Na}$ ausência de tais regras, a obrigação de gerir os negócios sociais incumbe a qualquer sócio $(D .17,2,32),{ }^{74}$ dentro dos limites do objeto social, desde que os demais não se oponham ${ }^{-5}(D .10,3,28$ pr.). Mais do que uma faculdade, a gestão dos negócios sociais é, antes de tudo, uma obrigação dos sócios. ${ }^{76}$

Em relação à administração da sociedade, Amó ${ }^{7-}$ ensina que pode ela ser confiada a um só sócio, que age como mandatário e, como tal, não pode transigir (D. 3 , $3,60)$; a mais sócios (D. 14, 1, 1, 13 e 14); a um estranho, que atue como mandatário ou locatur operarum (D. 17, 2. 16 pr. e 24) ou-não ser confiada a ninguém, prevalecendo neste caso o critério do ius prohibendi. ${ }^{78}$

6. A disciplina da responsabilidade dos sócios

Como nas demais relações que envolvem a administração de bens, na sociedade o problema em matéria de responsabilidade contratual consiste em saber se as perdas decorrentes da gestão dos negócios sociais devem ser imputadas ao sócio-gerente ou a todos os sócios, na proporção de suas quotas. ${ }^{79}$

Ao longo do desenvolvimento histórico do Direito Romano, a responsabilidade pelas perdas na gestão do patrimônio social é atribuida ora à sociedade,

\footnotetext{
7 Cf. Derecho romano classico. cit., p. 528.

7 Cf. GIRARD, Manuel..., cit., p. 577 e ARNÒ, Il contratro di socielà, cit.. p. 247-8. KASER, Derecho romano privato. cit. p. 204, ressalta que, no direito romano, o ordenamento juridico manifesta uma clara repugnância à intervenção na communio, na associação familiar e nas corporações.

7 Cf. GIRARD, idem, ihidem.

7 Trata-se do critério do ius prohibendi, previsto em $D .8,5,11 ; D .8,2,26 ; D .8,2,27,1: D .10,3,28$ pr.; D. $33,3,4:$ D. 8. 2. 8; D. 39. 2, 32; D. 10,3, 12 e D. 17.2, 52, 10 (cf. ARNÖ. Il contranto di sociera, cit., p. 248).

76. Cf. ARNÒ, Il contratro di socieià, cit., p. 247.

7 Idem, p. 248-254.

7 Vide nota $\mathrm{n} .75$ supra.

7 Cf. por todos, DE ROBERTIS. La responsabilità contrattuale nel sistema della grande compilazione. Bari, Cacucci. 1982-3. 2 volumes, vol. I, p. 861.
} 
ora ao sócio-gestor. E, conforme o periodo. a responsabilidade deste último oscila entre o dolo e a culpa. ${ }^{80}$

6.1. A discussão sobre a responsabilidade dos sócios no período clássico

A disciplina da responsabilidade dos sócios no Direito clássico é debatida tanto pelos juristas romanos quanto pelos atuais. Porém, a discussão ocorre de forma diversa. Em Roma, enquanto os servianos propugnam pela responsabilidade só por dolo, os mucianos defendem a aplicação também do critério da culpa. E uma terceira corrente afirma a imputação por dolo e por diligentia quam suis. Já entre os autores modernos, a corrente mais antiga parte da última concepção romana, sendo contestada pelos interpolacionistas que defendem a sua limitação ao dolo. E atualmente questiona-se o excesso interpolacionista, prevalecendo a tese dos que advogam a adoção do dolo e da culpa in abstracto.

Uma primeira corrente de opinião é formada pelos servianos, que acreditam na responsabilidade do sócio somente por dolo no período clássico. Sua doutrina é fundamentada pelas várias fontes que trazem expressa a imputação do sócio somente por dolo, bem como no princípio da boa-fé e no caráter infamante da actio pro socio.

Em oposição aos servianos, os mucianos defendem a extensão da responsabilidade contratual à culpa. O passo inserto em $D .9,2,31$ retrata o princípio geral da doutrina muciana. A polêmica entre ambos os grupos é atestada nas fontes, através da utilização dos termos quaeritur em $D .17,2,52,2$ e quaesitum est em $I .3,25$, $9 .^{81}$

Por fim, a partir do texto de Gaio, em $D .17,2,72$, identifica-se um terceiro entendimento, confirmando a responsabilidade por dolo e por culpa. mas sendo esta última nos limites da diligentia quam suis. O passo é o único na época clássica a mencionar a responsabilidade dos sócios por culpa in concreto. Somente mais tarde, tem-se $I .3,25,9$, no mesmo sentido e com redação parecida. Isto torna ainda mais dificil precisar a idéia de Gaio. Segundo Arnò, a intenção do jurista é estabelecer uma media sententia entre as teses serviana e muciana. ${ }^{82}$ Para aqueles que, com base em $D .16,3$, 32, acreditam que a diligentia quam suis é uma medida da culpa lata, a responsabilidade do sócio por culpa in concreto nada mais é do que a imputação por dolo, vez que a culpa

80 DE ROBERTIS, La responsabilità contrattuale nel sistema della grande compilazione. Bari, Cacucci, 1982-3, 2 volumes, vol. I, p. 861

81 Cf. ARNÓ. Il contratto di societá, cit., p. 254.

82 Idem. p. 254-255. 
grave a ele é equiparada ${ }^{83} \mathrm{Ou}$, então, Gaio pretende afastar a diligentia quam suis do dolo e aproximá-la da culpa. ${ }^{84}$

Apesar da culpa in concreto constituir, no Direito justinianeu, a medida da responsabilidade nas relações entre sócios, somente dois textos $(I .3,25,9$ e $D .17,2,72)$ a mencionam. Como os demais não especificam o grau de culpa, suspeita-se que as referências genéricas à culpa são devidas à utilização de textos elaborados na época pósclássica ou à origem clássica de cada texto. ${ }^{85}$ Já Arangio-Ruiz afirma ser desnecessária a discussão a respeito do genus culpae no periodo de Justiniano, pois as referências à culpa na compilação justininéia são simples remanescências pós-clássicas, uma vez que o critério da culpa foi substituído pelo da diligentia quam suis, introduzido por Justiniano. ${ }^{86}$

Passa-se à uma breve síntese da discussão entre os autores modernos sobre a responsabilidade dos sócios no período clássico. Tratando-se de exame das fontes, com indicação de possíveis alterações e revisão da crítica interpolacionista, será obedecida a ordem de debates entre os autores.

\subsubsection{A tese dos interpolacionistas: responsabilidade dos sócios somente por dolo}

Entendem os interpolacionistas ${ }^{87}$ que no Direito Romano clássico os sócios respondem somente por dolo e no Direito justinianeu também por culpa.

Um de seus principais argumentos consiste no fato da actio pro socio ser uma ação infamante e a pena de infâmia ter aplicação apenas nos casos de

83 Cf. HAUSMANINGER, Diligentia quam in suis, in Festschrift für Max Kaser zum 70 Geburtslag, organizado por Dieter Medicus e Hans Hermann Seiler. München, Beck. 1976, p. 27I-276.

84 Cf. MAYER-MALY, De se queri debere. officia erga se und Verschulden gegen sich selbst, in Fesischrift für Max Kaser..., cit., p. 229-264, à p. 241 e ss..

85 Cf. BETTI, Imputabilità dell 'inadempimento dell obbligazione in Diritto Romano. Roma, Ricerche, 1958, cit., p. 262-3 e DE ROBERTIS, La responsabilitá contrattuale..., cit., p. 877-8.

86 Cf. La socielà..., cit., p. 189-190.

87 Cf., entre outros, BRAßLOFF, Textkritisches zu römischen Rechtsquellen, in Wiener Studien 24 (1902), p. 563 e ss, apud ARANGIO-RUIZ, Responsabilitá contrattuale in diritto romano, 2. ed., Napoli, Jovene, 1933, p. 45, nota 2: MITTEIS. Römisches Privatrecht bis auf die Zeit Diokletians I. Leipzig, Duncker \& Humblot, 1908, p. 330, nota n. 43; KÜBLER, Das Utilitätsprinzip als Grund der Abstufung bei der Vertragshaftung im klassischen römischen Recht, in Festgabe für Otto Gierke II. Breslau, Marcus, 1910, p. 235-275, p. 252-256 e 273-275; PEROZZI, Istituzioni di diritto romano, II, 2. ed., Roma, Athenaeum, 1928, p. 303; KUNKEL. Diligentia, ZSS 45 (1925), p. 266-351. p. 272 \& 287; ARANGIO-RUIZ, Responsabilità contrattuale.... cit., p. $43-48$ e La societu.... cit., p. 188 e ss.; DEL CHIARO, Le contrat de société..., cit., p. 189-190; EHRHARDT, Diligentia quam in suis, in Mnemosyna Pappulias. Athen, Pyrsos, 1934, p. 101-141. à p. 139; WIEACKER, Haftungsformen des römischen Gesellschaftrechts, ZSS 54 (1934), p. 35-79, e Societas..., cit., p. 5; LUZZATTO, Caso fortuitu e forza maggiore come limite alla responsabilitá contratmale l: La responsabilità per custodia. Milano, Giuffri. 1938, p. 182 et seq. SEIDL. Römisches Privatrecht. Bonn, Verlag. 1963, p. 111-112 e 153-154, e IGLESLAS, Derecho romano. Instituciones de derecho privado, 9. ed., Barcelona. Ariel. 1985. p. 450. 
responsabilidade só por dolo. Até quem defende a originalidade das fontes que mencionam a imputação por culpa concorda com o argumento, acrescentando que não se pode deixar de atribuir importância à distinção entre as ações infamantes e não infamantes no Direito Romano.$^{88}$ Não-obstante. Talamanca ${ }^{89}$ lembra que o dolo não é um critério exclusivo nem para os próprios interpolacionistas, que apontam também a custódia como critério de imputação no âmbito dos iudicia bonae fidei, trazendo o problema da compatibilidade ou não da responsabilidade por culpa com as ações de boafé. No entanto, como já foi visto, discute-se se a custódia é ou não um critério de responsabilidade no período clássico. E. mesmo sendo a resposta positiva, a custódia representa um parâmetro da responsabilidade objetiva, permanecendo o dolo como medida única da responsabilidade subjetiva.

Nas fontes há vários indícios de que o dolo é o único critério de responsabilidade no período clássico ou em grande parte dele. A Tabula Heracleensis, do ano 40 a.C., enumera a actio pro socio entre os iudicia, fazendo referência apenas ao dolo: "queive iudicio fiduciae pro socio tutelae mandati iniuriarum deive dolo malo" (1111).

Um contrato celebrado no ano de 167 d.C.. conservado numa tabuleta descoberta na Transilvânia, junto com outros documentos, também atesta o dolo como critério único de responsabilidade:"....si quis d[olo mal]o fraudem fec[issede] prehensus fue [rit]" in

No Digesta diversas passagens indicam somente a responsabilidade por dolo. como D. 2, 13, 9 pr.; D. 17, 2, 59, 1; D. 17, 2, 58, 2; D. 17. 2, 3, 3; D. 17, 2. 63, 7 e D. 17, 2. 40. Já em $D .10 .2 .25,16$, como a justificativa da responsabilidade por culpa do co-herdeiro é o fato de não estar vinculado a um contrato, pressupõe-se que não deve haver responsabilidade por culpa nas relações contratuais.

Não-obstante as fortes razões apresentadas, a tese encontra seu obstáculo na aplicação do princípio da ufilitas contrahentium já na época pós-clássica, bem como nos inúmeros textos que mencionam a culpa. Porém, argumentam os interpolacionistas que as fontes que expressam o princípio da utilidade também são bastante suspeitas de interpolação. Já aquelas que fazem referência à culpa. dentre as quais D. 17. 2. 52, 2 é o mais significativa. demonstram ou que o instituto é aplicado apenas em casos

\&s A propósito, ARNÒ. Il contrallo di socièà, cit., p. 264, reconhece que "Ai serviani, in questa loro ragione di decidere per la limitazione della responsabilità al dolo, non facevano difetto le argomentazioni. (...) Non si può non attribuire la debita importanza alla distinzioni tra azioni infamanti e quelle non infamanti per tutto quanto si attiene alla misura della responsabilitá contrattuale".

s9 Cf. Colpa crivile (storia), ED 7 (1960). p. $517-534$ e Società (diritto romano). in ED 42 (1990), p. 814-860, à p. 855 .

90 Cf. BRUNS. Fontes iuris romani antiqui, 7. ed.. Nachdruck. Malen. 1958. p. 376. 
excepcionais, contrariando a regra geral e o caráter infamante da actio pro socio, ${ }^{91}$ ou que não é um critério de responsabilidade e sim a causa da perda de uma vantagem. ${ }^{92}$ Todavia, como não são poucos os textos relativos à culpa, difícil entendê-la como uma medida adotada apenas em situações particulares. Por outro lado, como se referem tanto à culpa como à diligentia quam in suis, indicam a menção a um critério de responsabilidade.

Por fim, sendo correta a premissa interpolacionista, estranha-se o fato de nenhum jurisconsulto ter questionado, durante os três séculos de período clássico, a responsabilidade apenas por dolo, ${ }^{93}$ o que não impede que a culpa tenha aplicação pósclássica ou limitado uso clássico.

\subsubsection{A defesa da autenticidade das fontes: responsabilidade por dolo e culpa levis in concreto}

A ofensiva interpolacionista é rebatida pelos autores que confiam na genuinidade dos textos, como Sertorio ${ }^{94}$ e Arnó. ${ }^{95}{ }^{96}$

Para Arnó, ${ }^{97}$ ao contrato de sociedade aplica-se originariamente a responsabilidade só por dolo, por influência da doutrina serviana. A seguir começa a prevalecer a tese muciana da responsabilidade também por culpa, de acordo com o princípio geral exposto em $D .9,2,31 \mathrm{E}$ alguns juristas servianos, entre os quais Gaio, adotam uma terceira postura, que denomina de media sententia, defendendo a aplicação da responsabilidade por dolo e diligentia quam in suis rebus adhibere solet. Para tanto, fundam sua argumentação na genuinidade do texto de Gaio, em $D .17,2,72$, eis que tem o mesmo sentido e quase as mesmas palavras das Institutas de Justiniano $(I .3,25,9)$. Ainda que os passos sejam autênticos, não se consegue explicar porque apenas dois textos relativos à societas mencionam tal forma de responsabilidade, quando inúmeras

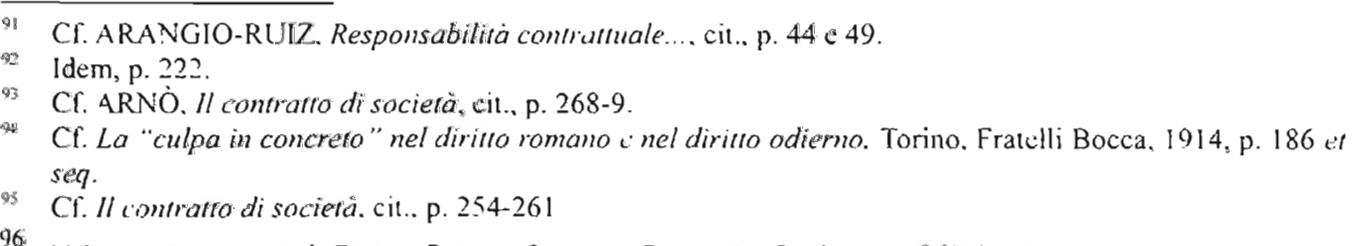

Volterra. Istituzioni di Dirino Privain Romano. Roma. La Sapienza, 1961 (trad. de Jesús Daza Martinez. Instituciones de Derecho Privado Romano. Madrid. Civitas, 1991). p. 523, menciona a responsabilidade nos limites da culpa in concreto, embora ressalve (idem, nota 184) que parte da doutrina sustenta que tal critério foi introduzido pelos compiladorts e por isto defende a responsabilidade no direito clássico por culpa levis.

$v^{-} \quad$ Idem. p. $254-255$. 
outras passagens fazem referência só ao dolo ou ao dolo e à culpa. E a coincidência de D. 17,2, 72 com uma fonte justinianéia agrava a suspeita de alterações.

Apesar de parte da doutrina sustentar que a diligentia quam in suis é pósclássica ou introduzida ao tempo de Justiniano, ${ }^{98}$ não se pode descartar a hipótese deste critério de responsabilidade, por exigência das relações negociais, ter sido inicialmente aplicado no contrato de sociedade e depois estendido aos demais institutos. Isto porque, de todos os textos que fazem menção à diligentia quam suis, o menos atacável, em relação à sua originalidade, é aquele que se refere à societas.

$\mathrm{Na}$ defesa da autenticidade das fontes, também é lembrado que outros jurisconsultos utilizam o critério da culpa in concreto para determinação da responsabilidade em institutos diversos. Como Paulo, para quem a culpa in concreto é o parâmetro adotado na comunhão incidental $(D .10,2,25,16)$ e na administração dos bens dotais $(D .23,3,17$ pr.). Tal argumentação encontra seu ponto fraco na contradição com outros escritos do autor, como D. 2, 13, 9 pr., além das diversas suspeitas de interpolação que seus textos oferecem, principalmente $D .23,3,17$ pr. Já as possíveis interpolações em textos de Ulpiano (D. 26.7,33 pr; D. 27, 3, 1 pr. e D. 36, 1, $23(22), 3)$ indicam que o jurista jamais aplicou o critério da culpa in concreto. O possivel remanejamento dos textos ulpianeus, todavia, não é fator impeditivo à utilização da diligentia quam suis por Gaio, em relação à imputação dos sócios (D. 17, 2, 72). e por Paulo $(D .10,2.25,16)$, para definir a dos comunheiros. ${ }^{99}$

Segundo Arnò, ${ }^{100}$ a razão da aplicação deste critério aos casos de pessoas que gerenciam coisas alheias junto com as próprias (não só na sociedade, mas também no condomínio e na administração do patrimônio da esposa e do pupilo) é simples: pressupõe-se que a pessoa cuide dos negócios da forma mais zelosa possível, como se fossem os seus próprios, e se ela não trata melhor é porque não sabe ou está acima de suas forças.

\footnotetext{
98 Cf. os autores mencionados por RIBFIRO, "Societas": a responsabilidade dos sócios no direito romano e seus reflexos no direito moderno, dissertação. São Paulo, FDUSP, 1996. p. 48-49.

99 Cf. ARNÒ, 11 contratto di sncietà, cit., p. 260.

100 Idem, p. 255.
} 
6.1.3. A doutrina muciana: responsabilidade dos sócios por dolo e por culpa levis in abstracto

Autores mais recentes, dentre os quais destacamos Pflüger, ${ }^{101}$ Kaser, ${ }^{102}$ Laffly, ${ }^{103}$ Talamanca $^{104}$ e De Falco ${ }^{105}$ rebatem a tese interpolacionista e defendem a idéia muciana da responsabilidade por dolo e culpa in abstracto.

Fundam-se na regra geral em $D .9,2,31$ e no princípio da utilitus contrahentium. Como no contrato de sociedade ambas as partes auferem uma vantagem, os sócios devem responder por dolo e culpa, sendo a última nos limites da culpa in abstracto. Os textos que embasam sua posição são aqueles que tratam do princípio da utilidade, como $D .13,6,5,2-3 ; D .13,6,5,15 ; D .50,17,23 ; D .19,5.17,2 ; D .30$, 108, 12 e Coll. 10, 2, 1, 2 e 4.

No tocante ao contrato de sociedade, vários textos mencionam a responsabilidade por culpa, sem especificar o seu grau: $D .17,2,52,2 ; D .50,17,23 ; D$. $17,2,52,11 ; D .17,2,51$ pr. e $D .17,2,65,9$. Sem referência à responsabilidade do sócio gestor, outros textos fazem menção expressa à culpa, como $D .17,2,23$ pr; $D .17$, 2. 52,$4 ; D .17,2,25-26$ e D. $17,2,36$.

Para os defensores da tese muciana, em todas as referidas passagens a omissão na especificação da culpa indica que a diligentia quam suis é introduzida no periodo justinianeu e somente são alterados os principais textos.

De Falco ${ }^{106}$ acrescenta ainda a Lex Irnitana, ${ }^{107}$ descoberta no início da década de 1980. Sua data precisa não é conhecida, mas como deve ser uma adaptação da Lex Iulia municipalis, provavelmente é elaborada um pouco depois de 17 a.C. ${ }^{108}$ A Lex Irnitana delimita a jurisdição municipal, estabelecendo a competência dos dummviri somente nas ações de sócio intentadas em razão de um comportamento doloso. o que aponta que o remédio processual pode ser utilizado também em outras hipóteses, ou seja,

101 Cf. Zur Lehre von der Hafiung des Schuldners nach römischem Recht, ZSS 65 (1947), p. 121-218, às p. 188-193.

102 Cf. Derecho romano privato, cit., p. 204.

103 Cf. Responsabilité du "socius" et concours d'actions dans la socièté classique, tese. Lausanne, 1979, p. 3 48.

104 Cf., por todos, Società..., cit., p. 855-856.

105 Cf. "Diligentiam praestare": Ricerche sull'emersione dell'inadempimento colposo delle "obligation's" Napoli, Jovene, 1991, p. 94-102 e 134-143.

los Idem, p. 138 ess.

107 Sobre a fonte, foram apresentados diversos estudos. Uma relação bibliográfica é indicada por D ${ }^{\circ}$ ORS. De nuevo sobre la ley municipal, SDHI 50 (1984), p. 179-198, à p. 179, nota n. I E. I.URASCHI, Sulla lex Irnitana, SDHI 55 (1989), p. 349-368. à p. 349-350 e notas ns. 3 a 14. 
no caso de culpa. A conclusão da autora, no entanto, esbarra na falta de referência à culpa no texto.

Por fim, como visto anteriormente, há elevada suspeita da culpa e do princípio da utilidade serem de origem pós-clássica, o que representa a maior objeção à aceitação da responsabilidade por culpa no período clássico.

\subsection{A culpa como base da responsabilidade dos sócios no Direito justinianeu}

No Direito justinianeu o gestor responde por dolo e culpa. Na obra de Justiniano tal orientação é bem clara, a começar pelo celebérrimo texto fundamental, inserto em $D .50,17,23$.

A responsabilidade nos limites da culpa in concreto é prevista em I. 3, 25, 9 , que segue as orientações já expressas em $D .17,2,72$ e nas Basílicas 12, 1, 70.

Sobre o emprego da diligentia quam suis como critério de imputação da responsabilidade dos sócios, a doutrina é praticamente quase unânime. ${ }^{109}$ embora somente dois textos $(D .17,2,72$ e $I .3,25,9)$ contenham previsão a respeito e muitos outros tragam referências genéricas à culpa. Isto reforça a tese de que os compiladores utilizam material pós-clássico já elaborado, sem o cuidado de especificar o genus culpue do qual tratam.

De qualquer forma, a escolha do critério da diligentia yuam suis deve-se não só ao fato de sua aplicação freqüente no Direito justinianeu, como também pelo seu caráter intuitu personae, mais pessoal que nas outras relações contratuais (como, por ex., o depósito e o mandato ${ }^{110}$ ), pois a parte deve conhecer e saber da diligência habitual da pessoa com a qual está constituindo uma sociedade. ${ }^{\prime \prime \prime}$

Outros textos confirmam a adoção do critério da responsabilidade do sócio por culpa, como D. 17, 2, 52, 1-2; D. 17, 2, 52,3; D. 17, 2, 52, 4; D. 17, 2, 23 pr.; D. 17. 2,25 e $26 ; D .17,2,35$ e $36: D .17,2,52,11 ; D .17,2,65,9 .^{112}$

109 A respeito, confira-se o rol trazido por DE ROBERTIS, La responsabilitá contrattuale..., cit., p. 866 , à nota $n$. 28, citando desde a antiga doutrina até os autores mais recentes.

110 No contrato de sociedade a relação intuitu personae é diversa e mais profunda do que nas demais relaçõts contratuais, como no depósito e no mandato. Nestes, somente a personalidade do devedor tem um papel determinante na formaçẫo do contrato (cf. SERTORIO, La "culpa in concreto"..., cit., p. 185-6, com apoio em HASSE). Mas. no primeiro (depósito) a diferença de tratamento é facilmente explicável em função da utilitas contrahentium, já que o devedor não lucra com o contrato. Já no mandato, a atividade do devedor é gerir os negócios segundo as instruções recebidas, de forma vinculada e funcionalmente subordinada, enquanto que na sociedade o gestor não se encontra em posição de subordinação (cf. DE ROBERTIS, $L a$ responsabilitá contrattuale..., cit., p. 867 , nota n. 39 ).

11' Cf. DE ROBFRTIS, La responsabilità contrattuale..., cit., p. 867-868. A opinião do autor pode ser facilmente auferivel nos textos, dentre os quais podemos destacar $I .3,25,9$ e D. 17, 2, 72.

"I Idem, p. 863, nota n. 8, onde o autor traz a indicação bibliográfica da interpretação de cada texto. 
Algumas contradições entre textos justinianeus explicam-se pela preocupação dos compiladores, em regra, de definir o regime de responsabilidade somente nas passagens principais, deixando aos intérpretes a tarefa de adaptar expressamente todas as fontes para qualificar o grau da culpa. ${ }^{113}$

Em razão do critério adotado pelos compiladores de Justiniano, os textos que atribuem a responsabilidade por dolo são objeto de reelaboração (v.g., D. 17, 2, 40 e D. 17, 2, 65,3), visando eliminar possíveis antinomias e dar uma unicidade ao sistema. ${ }^{114}$ Apesar disto, alguns contrastes persistem, como entre $D .17,2,40$, que insiste na responsabilidade por dolo e $D$. 17, 2, 36 que, num caso análogo, afirma o critério da culpa. ${ }^{115}$

Uma outra questão diz respeito à dúvida entre a distinção entre culpa in faciendo e culpa in omittendo nos textos. Tal indagação surge devido à utilização do termo quod si em $D .17,2,52,2$, o que dá a idéia de contraste entre as duas situações: a culpa por dano causado pelo sócio (própria do sócio normal) e a derivada da ausência de procura do ganho calculado (própria do sócio de indústria). Concluem os bizantinos que a imputação da responsabilidade pode ocorrer por ambas as razões.

No mais, o sócio responde pelo comportamento contrário aos deveres de lealdade e de diligentia, prevalecendo o interesse social sobre o interesse particular do sócio $(D .17,2,65,5)$.

A responsabilidade do sócio-gerente encontra seus limites no caso fortuito e na força maior. Com base na regra de $D .17,2,52,3$, tem-se que o sócio não responde pelos eventos que vão além de sua capacidade de previsão e prevenção, tais como o incendium, adgressura latronum e o naufragium. ${ }^{116}$ No caso de pericula, como os riscos atinentes à navegação e às viagens, somente deve ser suportado pelo sócio de indústria, uma vez que é um risco pessoal, que faz parte de seu aporte social $(D .17,2,5.1 ; D .17$, $2,52,2)$. A aplicação da custódia ao contrato de sociedade limita-se às hipóteses previstas em $D .17,2,52,2-3 .{ }^{117}$

7. O caráter intuitus personae da societas e seus reflexos nas relações sociais

113 DE ROBERTIS, La responsabilità contrattuale..., cit., p. 867-868. A opinião do autor pode ser facilmente auferivel nos textos, dentre os quais podemos destacar $1.3,25,9$ e D. 17, 2, 72. p. 878.

Iit Cr. DE ROBERTIS, idem, p. 862 e nota n. 4.

IIs Id. lbid., nota n. 5.

116 Id. Ibid., p. 868-9.

11 Cf. ARANGIO-RUIZ, La socieı́a.., cit., p. 191. 
Como visto, a societas romana é fundada $\mathrm{em}$ forte vínculo intuitus personae e na vontade contínua dos sócios (consensus). ${ }^{11 *}$ Por isto, qualquer alteração no vínculo original, ou seja, no quadro social (morte ${ }^{119}$ ou renúncia ${ }^{120}$ ) ou estado pessoal dos sócios (capitis deminutio ${ }^{121}$ ou insolvência ${ }^{122}$ ) implica a dissolução da sociedade ${ }^{123}(D$. 17, 2, 4, 1). Um sócio não podia ser substituído, nem a sociedade continuar na ausência ou modificação do status de seu membro.

A idéia de fraternidade, combinada com a necessidade de vontade contínua, é incompatível com a idéia de exclusão de sócio, ${ }^{124}$ justificando a solução romana de dissolução da sociedade.

Alguns dos motivos de dissolução da sociedade no Direito Romano coincidem com razões da exclusão hodiernas, como a mudança no estado do sócio ( $D$. $17,2,4)$ e a violação de deveres sociais $(D .17,2,14)$, derivados da idéia de recíproca confiança entre os sócios. ${ }^{125} \mathrm{Em} D .17,2,63,10$, são apontadas como causas voluntárias e ipso iure de extinção do contrato de sociedade, de quatro tipos: ${ }^{126}$ em razão das pessoas (morte, capitis deminutio ou quebra de um sócio, ${ }^{127}$ como nos casos de bonorum venditio, bonorum cessio ou confisco de todos os bens); das coisas (realização integral ou impossibilidade de cumprimento da finalidade social, perecimento ou transformação dos bens que compõem o patrimônio social em res extra commercium); da vontade dos sócios (a qualquer momento ou no fim do termo ao qual o contrato se subordina) ${ }^{129}$ ou de

118 I. $3,25,4 ; C .4,37,5 ; D .17,2,19 ; D .17,2,65,3$ e 9 , e $G .3,151$.

119 I. $3,25,5 ; D .17,2,52,9 ; D .17,2,59$, pr; D. 17, 2, 60, pr; D. 17, 2, 65, 9 e D. 17, 2, 65. 11.

120 D. $17,2,65,3$.

$121 G .3,153$. A capitis demimutio do sócio é equiparada à sua morte $(G .3,101$ e 153). Mais tarde, somenti a capitis deminutio máxima c média $(D .17,2,63.10$ e $D .17,2.65 .11)$

12 Cf. $G .3,152-153 ; D .17,2,4,1 ; D .17,2,52,9 ; D .17,2,59$ pr.; D. 17, 2, 63, 10; D. 17, 2, 65, 3 e $9 ; 1.3$, $25,4-5$. A perda dos bens pode ocorrer por quebra $(I .3,25,8 ; D .17,2,65,1)$ ou confisco de todos os bens (D. 48,20,1 pr; D. 46, $1,71 \mathrm{pr} ; I .3,25,7)$. O confisco de todos os bens também ć igualado á morte (I. 3 , $25,7 ; D .17,2,65,12 ; G .3,153)$

123 Ao contrário de hoje. no Direito Romano não há a distinção entrc dissolução, liquidação e extinção. Para a liquidação, utilizava-se a actio pro socio, cf. ARANGIO-RUIZ, La societá..., cit., p. 173 e ss.; TALAMANC:A, Socieia..., cit.. p. 850-854.

124 CF. DALMARTELI.O, L'esclusione dei soci dalle società commerciali. Padova, CEDAM, 1939. p. 2-3 e PERRINO, Le tecniche di esclusione del socio dalla societa. Milano, Giulìrè, 1997, p. 61, nota 2.

125 Cf. ARANGIO-RUIZ, La socielá..., cit., p. I5I.

126 Maiores detalhes podem ser encontrados em MOREIRA ALVES, Direito Romano, cit., p. 203-204.

${ }_{127}$ Cr. $D .17,2.65,1$, que fala em extinção da sociedade quando todos os bens do sócio são vendidos pelos credores.

128 D. $17,2,65,3 ;$ D. $50,17,35$. 
um só sócio (renuntiatio) ${ }^{129}$ e em razão de ação (quando um sócio pleiteia a dissolução da sociedade por meio da actio pro socio). ${ }^{130}$

O falecimento era causa de dissolução da sociedade, em razão da escolha pessoal dos sócios (quia qui societatem contrahit, certam personam sibi elegit). ${ }^{131}$ No caso de morte de sócio, se os demais quisessem continuar sócios, deveriam constituir nova sociedade. ${ }^{132}$ Nas sociedades privadas não era válida a convenção para ingresso dos herdeiros como sócios. ${ }^{133}$ Mais tarde foi admitida a estipulação, no contrato de sociedade, de cláusula permitindo a continuidade da sociedade com os sócios sobreviventes, em caso de falecimento de um deles. ${ }^{134}$ Apesar de ser regra excepcional, aplicada somente na hipótese de morte de sócio e não nas demais ensejadoras da dissolução, trata-se de primeira e tímida afirmação do princípio conservativo. ${ }^{135}$ Também

129 Exceto no caso de renúncia intempestiva, sem justa causa ou fraudulenta, caso em que a sociedade continua com os demais sócios. Ainda que se tenha convencionado que o sócio não poderia renunciar, tal avença é nula $(D .17,2,14)$, pois se exige o mútuo consenso permanente.

in D. 17. 2, 65 pr. Para CANCELLI, NDI XVII, p. 221 e ss, à p. 513, a extinção ex actione não é necessariamente procedimento judicial e sim fórmula que pode ser tanto negocial quanto processual. A extinção da sociedade através da actio pro socio é bastante questionada, a começar pelo fato de Modestino. em $D$. 17, 2, 4 não mencioná-la na enumeração das causas. ARANGIO-RUIZ, La società..., cit, p. 174179, sintetiza a opinião dos criticos, alegando diversas ruzões: suspeita de interpolação de $D .17,2,65$ pr: que a vontade interna só é caracteristica da doutrina pós-clássica e a extinção depende de uma declaração: se o sócio pode renunciar, não se justifica a existência de forma indireta; o fato do Direito regular duas situações juridicas divcrsas, como a extinção da obligatio ex contractu por efeito da litis contestatio c a renuntiatio como formas de extinção da sociedade e a ausência de fórmulas processuais.

131 Cf. I. 3, 25, 5 e $G .3,152$.

${ }_{132}$ I. 3. 25. 8: D. 17,2, 35; D. 17, 2, 59, pr. e 1, e (i.3. 153.

D. $17,2,59 \mathrm{pr}$.

134 D. $17,2,65,9$ e $1.3,25,5$. Porém, era vedada a convenção de continuidade da sociedade com o sobrevivente e os herdeiros do sócio falecido $(D .17,2,35 \mathrm{pr}, D .17,2,52,9 ; D .17,2,59$, pr).

135 Cf. BRINZ, Lehrbuch der Pandekten, citado e apoiado por DALMARTELLO, L'esclusiune..., cit., p. 4; VILLAVERDE, La exclusión de socios: causas legales. Madrid, Montecorvo, 1977, p. 31. Não obstante falar-se em princípio conservativo, parcce que a finalidade da regra não é a proteção da empresa. mas a razão prática de evitar que os sócios remanescentes tenham que constituir nova sociedade. 
na societas publicanorum ${ }^{176}$ e na societas vectigalis não há a extinção da sociedade pela morte de sócio (D. 17, 2, 59 pr.; 63, 8).

Os romanos tiveram a preocupação de evitar que um membro causasse prejuízo aos demais. Em D. 17.2, 14, in fine, questiona-se a situação de sócio molesto e prejudicial, dificil de ser tolerado. Outras hipóteses já previstas são o perecimento de bem conferido à sociedade ${ }^{137}$ e por perdas de bens por motivos alheios às atividades sociais. $^{13 x}$

Tal preocupação é mais visivel nas regras sobre a renúncia do sócio. Como a sociedade exige mútuo consenso, não há como impedir a renúncia de sócio. Daí o estabelecimento de regras para defesa dos demais sócios, para evitar a renúncia intempestiva, ${ }^{139}$ fraudulenta ou com o propósito de prejudicar os demais sócios. ${ }^{140} \mathrm{~A}$ renúncia deve ser justificada. ${ }^{141}$ Como a conduta intolerável de um ou mais sócios, ${ }^{142}$

1'6 As societas publicanorum eram formadas por publicanos, agentes do Tesouro encarregados do lançamento e da arrecadação de tributos. Representam uma espécie particular no Direito Romano, apresentando diversas caracteristicas peculiares, que se aproximam das atuais companhias, como personalidade juridica. No entanto, a matćria não ć pacifica na doutrina, como aponta CIMMA. Ricerche sulle societá di publicani. Milano, Giuffrè, 1981, p. 163 c ss., negando a personalidade jurídica na época republicana, mas não descanta a possibilidade de desenvolvimento de embrião (personalidade incipiente), dados alguns fatores, como o caráter representativo do magister e dos decumani membros de um conselho de administração), a não extinção pelo talecimento de sócio, a incomunicabilidade dos bens da sociedade e dos sócios, o que demonstra uma limitação na responsabilidade individual c a possibilidade de alicnação das partes sociais a terceiros (CICERO, P. Vat. interr. 12, 29; pro Rab. Post. 2, 4). Sua administração é confiada anualmentc a um ou mais magistri, que cuidam da gestão dos negócios sociais, sendo assistidos por conselho administrativo composto por certo número de sócios principes el quasi senatores publicanorum (CICERO, in Verr. 2, 2, 71, 175).

Apesar de parcela da doutrina enxergar na societas publicanorum um germe das atuais sociedades anônimas, as diferenças são grandes e essenciais: a societas publicanorum demanda o exercício de função pública, a situação do socius não é comparável à do acionista (por exemplo, em matéria de direitos essenciais), nem a par's tem as caracteristicas e o regime de transmissão das ações. razões pelas quais não se pode conceber a sociedade anònima como produto de sua evolução, como explica CORREIA, Os administradores de sociedades anónimas. Coimbra, Almedina. 1993, p. 78 e notas, com indicação bibliográfica.

Cf. D. $17,2,58$, pre 1 .

D. $17,2,59,1$.

139 A renúncia intempestiva caracteriza-se pela saida de sócio antes do prazo determinado no contrato. Como a sociedade caracteriza-se por um consenso contínuo, a falta de intenção de permanecer como sócio provoca a dissoluçào da sociedade. Nu entanto, quem renuncia desobriga os demais sócios e a sociedade, mas não se libera de suas obrigações, exceto se a renúncia for fundada em justo motivo $(D .17,2,65,3$ e 6).

140 D. 17, 2, 65, 3: I. 3, 25, 4.: G. 3, 151. Como a socictas romana podia englobar todos os bens $(G, 3,148)$, no caso de um sócio receber um determinado proveito, como uma herança de um terceiro, e renunciar à sociedade, para nāo dividir o valor recebido com os outros sócios, lica obrigado ao ressarcimento dos demais.

(4) D. $17,2,16$ pr: $:$ D. 17. 2, 65, 6.

142 D. 17, 2. 14. ao final. 
desentendimento entre os sócios ${ }^{143}$ e ausência de sócio. ${ }^{144} \mathrm{Em}$ caso de renúncia em momento não favorável à venda dos bens da sociedade, deve o renunciante responder pelos prejuízos. ${ }^{14 s}$

O Direito Romano, portanto, procura preservar o Direito Privado do sócio, evitando prejuízos causados por outro membro. Mas não se nota a preocupação com interesse da empresa, noção, aliás, desconhecida à época. Tivessem os romanos a preocupação com a preservação da empresa, não seria vedada a constituição de sociedade in aeternum $(D .17,2,70)$, nem tido como nulo o pacto de não-dissolução $(D$. $17,2,14)$.

\section{Considerações finais}

A provável origem da sociedade romana a partir do consortium ercto non cito traz uma influência muito forte sobre suas regras e principais características. Destaca-se o caráter intuitus personae, no qual se baseiam as relações sociais. Assim, em estudo de Direito Comparado, conhecer a societas romana é importante para compreender as sociedades simples. Quanto às sociedades comerciais, a societas romana aproxima-se mais do modelo das sociedades de pessoas. mas com forte ligação íntima entre os sócios, sem muita preocupação com a manutenção da sociedade em razão de vicissitude pessoal de algum deles.

Em relação à administração, verifica-se ampla liberdade contratual para estabelecimento das regras, reforçando o caráter contratual da societas romana. O problema da aferição da responsabilidade decorre da evolução e formação das regras sobre a matéria, em razão da busca, pelos romanos, de soluções mais apropriadas aos casus concretos.

São Paulo, setembro de 2006.

143 D. 17, 2,65.3.

is $D .17 .2,17,1 ; D .17,2,2$. Quando o sócio deva se ausentar por longo periodo em razão de causa pública, ele só poderá administrar a sociedade atravis de outra pessoa. desde que seja muito solvente (o sócio) ou fácil a gestão da sociedade por outro $(I) .17,2,16)$.

$145.17,2,65,5$. 